\title{
New technologies, old dilemmas: theoretical and practical challenges in preschool immersion playrooms
}

\author{
Joanna McPake, School of Education, University of Strathclyde \\ Christine Stephen, School of Education, University of Stirling
}

\begin{abstract}
This paper describes some of the findings emerging from a design based research study investigating the potential of a tablet app, Our Story, to enhance language learning opportunities for children in Gaelic-medium preschool playrooms.
\end{abstract}

Gaelic-medium education plays a significant part in the Scottish Government's strategy for revitalising the language. However, relatively few children in Gaelic-medium classrooms now come from Gaelic-speaking families, though their parents are keen for their children to learn Gaelic and become bilingual. Thus, many children first encounter Gaelic in the preschool playroom, effectively a language immersion setting. Maximising children's exposure to the language and enhancing their use of it is an ongoing challenge for preschool practitioners.

There is very limited specialist initial or continuing professional education for preschool practitioners working in Gaelic-medium playrooms. Although there is an extensive international literature on immersion education, this focuses mainly on the outcomes, with little attention to the early stages of the process. Therefore, we know little about how preschool practitioners go about the task of introducing young children to the new language that will become their medium of instruction, nor how effective practice in this context might be defined or measured.

The study on which this paper is based, Ar Stoiridh, was funded by the European Regional Development Fund Programme Innovation Voucher Scheme, and conducted in collaboration with Stòrlann, the organisation charged with co-ordinating the production and distribution of Gaelic educational resources throughout Scotland. It was a small-scale pilot study, to trial a tablet app, Our Story. The intervention drew on design-based research, a methodology for investigating the relationships among educational theory, designed artefact and practice (Design Based Collective, 2003). A significant feature of this approach is close collaboration between researchers and practitioners in identifying the problem to be addressed by the intervention and refining, through successive iterations, the solution. Detailed documentation of the process enables the researchers to keep track of practical barriers or facilitators, and often leads to design changes. In this case, it emerged that there were marked differences between the researchers' and the practitioners' beliefs about effective language learning in the early years, a finding which would have had a bearing on the development of the design beyond the pilot phase. It is argued that this finding has implications for theoretical understanding of how preschool practitioners set about supporting children as they learn a new language in immersion-style settings; and of how to design practical interventions, such as the use of digital technologies to support early language learning or professional development for preschool practitioners in such settings. (421 words) 


\section{Introduction}

Education through the medium of a minoritised language is one of the main ways by which the revitalisation of that language can be supported (Hinton, 2001; McCarty, $2002 \& 2008$; May, 2004; Tedick et al., 2011). Such provision enables children growing up in families and communities where the language is still spoken to develop literacy and expands the range of contexts in which they are able to use the language to include academic domains. In families where the dominant language is (now) spoken, parents may choose to send their children minoritised language medium (MLM) education to revive a language once spoken in the family, to support the revitalisation project for political or cultural reasons, or to enable their children to become bilingual, in recognition of the benefits - cognitive and practical - which bilingualism is known to confer. (See Hermanto et al., 2012, for a summary of recent research on this issue.) Although this paper focuses on Gaelic-medium education specifically, we believe that many of the issues raised here will be relevant to other contexts where MLM education plays a significant role in language revitalisation initiatives, particularly as we have found that preschool provision is under-represented in the literature on MLM education. ${ }^{1}$

Gaelic-medium education (GME) was (re-)established in Scotland in the 1980s, following a century or more of neglect (Campbell, 1950; Dorian, 1981; MacKinnon, 1978; Paterson, 2003). Provision is currently available in 60 primary schools, three of which are 'all Gaelic' schools, while in the remainder, Gaelic 'units' or 'streams' are incorporated into otherwise English-medium schools. The intention is that children in GME classrooms should be educated wholly through the medium of Gaelic in the early years, with English introduced as a second language mid-way through the primary phase, i.e. around age 7 to 8 . Although this provision developed originally in the Western Isles of Scotland (Murray \& Morrison, 1984), GME has become popular with English-speaking families and in areas of Scotland where Gaelic has a limited presence. Parents who are not Gaelic-speakers choose GME for their children for a variety of reasons, which range from a commitment to revitalising a language which is in danger of dying out, to a desire to enable their children to become bilingual from an early age. Though there are no definitive statistics, it is likely that fewer than $20 \%$ of children enrolled in GME are from Gaelic-speaking families (Pollock, 2010). Thus for the majority, GME is effectively language immersion education, where the parents of children who speak one language at home choose to have them educated through the medium of another at school. At the start of their educational careers, these children therefore encounter a playroom or a classroom where staff speak in a language they do not initially understand, with the expectation that they will come to understand and to use this language in time.

For most children in Scotland, their first experience of formal education is in pre-school, as they are entitled to two years of state-funded preschool education, constituting 475 hours per year, between the ages of 3 and 5. There were 730 children enrolled in GME nurseries for academic year 2011-2012, and also 730 enrolled in voluntary preschool provision (Galloway, 2012); but the National Plan for Gaelic 2012-2017 (Bòrd na Gàidhlig, 2012), whose purpose is to increase the number of people of all ages learning and using Gaelic, seeks a substantial increase in this number by 2017. Thus it is important that those enrolling now experience a positive and effective start to their GME careers, both to ensure that this group continue within the GME system, and to encourage others to choose this model for their children in future years. However, there are various types of pre-school provision in Scotland, including state and privately-run nurseries, playgroups and childminders, and the nature of their Gaelic

\footnotetext{
${ }^{1}$ The work of Hickey is an exception: see in particular Hickey (2013), Hickey et al. (2014) and earlier work such as Hickey (1997).
} 
provision is likely to differ quite considerably from one setting to another. Moreover, preschool practitioners also vary widely in terms of initial qualifications and opportunities for subsequent professional development. Formal professional development provision in Scotland specifically targeting preschool practitioners in GME has been very limited.

\section{Use of Gaelic in Gaelic-medium preschool settings}

Specifically what is meant by education through the medium of Gaelic is complex and controversial. An early project in the Western Isles envisaged a 'bilingual curriculum' which combined instruction in Gaelic and in English (Murray \& Morrison, 1984: p4 and passim). At thetime, over $90 \%$ of the pupils concerned could speak Gaelic and all but two of the 54 teachers involved in the project were fluent Gaelic speakers. The model of bilingual education adopted, some decades before the emergence of the theoretical concepts of heteroglossia (Heller, 2007; Bailey, 2007), recursive bilingualism (García, 2009) and translanguaging (García, 2007; Creese \& Blackledge, 2010) emphasised the inter-relatedness of the children's linguistic worlds, within and outwith the classroom, as well as the teacher's own linguistic attitudes, experiences and aspirations, and his or her engagement in the school and the wider community. It did not therefore prescribe the roles of Gaelic and English in the classroom, but rather sought to identify how both languages might be used naturally, specifically - and deliberately, for these very reasons - in the context of 'environmental studies' (a Scottish curricular term referring to the holistic teaching of history, geography and science in primary schools). This was a project undertaken by a development team and by teachers who were part of the local community and almost all of whom used both English and Gaelic in their daily lives. They were therefore familiar and comfortable in a community in which 'flexible bilingualism' (Creese \& Blackledge, 2011) was the norm.

However, although the early phase of this project engendered considerable enthusiasm and goodwill among teachers, children and the wider community, the difficulties children had in using Gaelic for curricular purposes (oral and written) became very apparent. After a century of educational practice which had equated English with academic and career success, and Gaelic with a fast disappearing rural way of life (Devine, 1994: 98), re-introducing Gaelic as a language for learning in a school context represented a very signficant challenge:

"What the teachers were being asked to do was neither simple nor easy. They were being encouraged to introduce changes in the content of the curriculum, to incorporate knowledge which was to be gleaned from community resources as much as, if not more than, from books. They were being asked to contribute relevant teaching materials linked to that content. They were being asked to anchor the work of the school in the everyday life of the children in the villages. They were being asked to adopt a teaching style which stressed the child's potential for sustained personal learning. And they were being asked to aid the child in developing all aspects of two linguistic codes against an evolving pattern of skills and concepts."

(Murray \& Morrison, 1984: 156-7)

In this context, a number of factors combined to shift the bilingual model originally adopted towards one promoting Gaelic as the sole or principal language of the classroom. These included frustration that the bilingual model did not lead to academic competence in Gaelic comparable to that which the pupils achieved in English, even when those pupils were fluent Gaelic speakers, taught by fluent Gaelic speakers. In fact, despite the project, it was clear that the numbers of fluent Gaelic-speaking children in the Western Isles were in steep decline, 
while the numbers of monolingual English children in the classroom were on the rise. ${ }^{2}$ According to Mitchell, who conducted an independent evaluation of the project, the larger the number of monolingual English speakers in the classroom, the less Gaelic was used (1992: 114). Thus it came to be felt that a relatively informal but contextually nuanced bilingual model which assumed that pupils already possessed a level of domestic or social, if not academic, competence in the language, and that they could draw on the Gaelic of the wider community as a resource, was not sustainable. Mitchell (op.cit.: 124) noted changing perspectives towards the end of the 1980s:

"Alarmed at the continuing advance of English among children in Gaelic-speaking areas, educationalists with a comitment to language maintenance have argued increasingly that schooling must become entirely Gaelic-medium (rather than bilingual) if the language shift is to be stemmed. This feeling is evident in the devleopment of the Gaelic playgroups movement and also in demands in a number of localities for Gaelic-medium primary schooling."

Thus the 'bilingual model' was replaced by a commitment to 'Gaelic-medium', in which there was a formal expectation that children would be educated through Gaelic alone in the early years.

As Creese \& Blackledge (2011) note, a commitment to 'language separateness' reflects an ideological position, usually adopted in relation to the maintenance of a 'minority' language such as Gaelic or a 'community' language such as Bengali or Turkish when these languages are in use in a context where another language is dominant (i.e. English in the case of the UK). They note too that despite a rhetoric of monolingual use of the minority or community language in educational contexts, this is rarely achieved in practice. They suggest that it would be more appropriate to recognise 'flexible bilingualism' where pupils and teachers can draw on both languages as they wish, to tackle classroom tasks. They argue that it is this flexibility to use all the linguistic resources at their disposal is what characterises bilinguals, rather than a formally developed competence in two languages, and that attempting to establish provision which separates the two languages is effectively arguing for 'parallel monolingualism'.

We acknowledge the theoretical force of this position but see it as a problematic principle in this particular context. Firstly, such a position would be viewed with consternation by those who view GME as a critical tool in the revitalisation project, given the difficulty of establishing Gaelic as a legitimate language to use in classroom contexts, and the risk that the language will disappear entirely within a generation as a result. Secondly, we are unsure how very young children who are just beginning to learn Gaelic will acquire the kinds of linguistic resources which would allow them to adopt flexible bilingualism if there are few situations or none at all - in which they can have extensive exposure to the language. Thirdly, while we agree that more complex and more speaker-centred models of multilingualism in practice need to be developed, researched and understood, we would argue that this needs to be sensitive to the challenges of acquisition and maintenance of the non-dominant language. Particularly when the dominant language is English, a language which is well-established as extremely pervasive and culturally attractive, the choice may effectively be between 'parallel

\footnotetext{
${ }^{2}$ See MacKinnon, 2006, for a summary of findings from a series of language surveys conducted in the Western Isles in the 1970s and 1980s, confirming this perception at the time. Between the 1981 and 2001, according to the Census, the proportion of children in the Western Isles aged 3-15 who could speak Gaelic fell from $68 \%$ to $46 \%$.
} 
monolingualism' and 'one-track monolingualism' (in English only), rather than 'flexible bilingualism'.

A consequence of Creese \& Blackledge's argument may be that education is not an appropirate milieu for achieving language revitalisation (an issue explored in detail in Hornberger, 2008). We recognise that our account of the dilemmas we report below in relation to how best to integrate a commitment to effective and engaging early years provision with a the goals of early language immersion reflects a position which assumes that education can play such a role. This is the espoused purpose of GME policy in Scotland. Thus our discussion below is based on the policy expectation that early years providers should be using Gaelic as much as possible in order to enable the pupils to acquire a strong basis in the language, before the formal introduction of English at age 7 or 8. Practitioners themselves often state that their aim is to create an environment which is ' $100 \%$ Gaelic'. However, our earlier research revealed that GME early years practitioners experience considerable difficulty in achieving this, given that most have had limited professional education, and almost certainly none in relation to language learning and teaching. Thus few are aware of contemporary theories of bilingualism, or are in a position to plan for the desired linguistic transition.

In 2008-9 we conducted a Review of Gaelic-medium early education and childcare (reported in [author(s) deleted]) on behalf of Bòrd na Gàidhlig and the Scottish Government. At that time we found 127 providers who defined themselves as 'Gaelic-medium', in 14 of Scotland's 32 local authorities (municipalities). Provision was available not only in the Gàidhealtachd (the Gaelic 'heartlands' in the north-west of Scotland, where Gaelic is most widely spoken) but also in the Central Belt (the highly populated area which includes Scotland's largest cities, Edinburgh and Glasgow, their surroundings, and the area between the two cities). In this study, based on questionnaires and interviews with key informants, we investigated the extent to which Gaelic was used in these settings. Just over half of our respondents indicated that all staff employed in their setting were fluent Gaelic speakers, and half said that staff used Gaelic 'at all times and for all activities'. However, only a third said that the language of the setting was Gaelic only. There could be several explanations for this, but one likely factor was that few parent helpers were Gaelic speakers: over half of the respondents reported that none, or only a few could speak Gaelic fluently. These data begin to indicate the complexities of attempting to establish an immersion-style model for Gaelic-medium preschool provision: there were not enough preschool practitioners fluent in Gaelic, and even if there were, it would still be likely that English would 'intrude' into the setting because few parents, parent helpers and other visiting adults spoke Gaelic. As has already been noted, few of the children were likely to have had opportunities to learn Gaelic before starting preschool, and so, at least at the start, would also use only or mainly English to speak to staff or to each other.

To investigate this further, we conducted a second study, Young children learning in Gaelic. The aim was to create a profile of the language-learning environment in Gaelic-medium preschool settings. The research was based on case studies of three Gaelic-medium preschool settings which we visited six times over the course of academic year 2010-11. It involved systematic observations of six children in each setting, and structured conversations with the children, towards the end of the year, concerning their own experiences of learning and using Gaelic. (For a summary of methods and outcomes, see [author(s) deleted]; for a broader discussion of the findings than possible here, [author(s) deleted]) From our observational data, a short snippet illustrates some of the challenges facing practitioners seeking to achieve the goal of making their playrooms Gaelic-only environments: 
Two girls were in the nursery 'home corner', an area filled with cushions and toy domestic items such as a cooker, table, crockery etc. The nursery's theme during this period was 'people who help us' and they had been finding out about the work of doctors and nurses. This may have influenced the role-play in which they were engaged. Ms C., one of the preschool practitioners working in the nursery, passed by the home corner while they were playing and the following short conversation was recorded in the researcher's notes:

M: I'm pretending in the game that I'm ill.

Ms C: Dè tha ceàrr ort? (What's wrong with you?)

L: They don't know.

Ms C: Dè tha an dotair ag ràdh? (What's the doctor saying?)

M: I don't know.

At this point, the children got up from the home corner cushions on which they had been lying and moved away to another part of the nursery.

A number of features of the language-learning environment come to the fore in this extract. Firstly, as our research found was the norm in Gaelic-medium preschool settings, though the practitioner spoke in Gaelic, the children replied in English, with no attempt to use any Gaelic. It is not clear whether or not they understood Ms C's questions. The responses made sense in the context of the discussion, but they were also ambivalent, and it was possible that the children had learnt to produce vague responses to Gaelic conversations that 'work' in terms of seeming to maintain the conversation, while avoiding deeper engagement which might reveal a lack of comprehension or an ability to discuss the topic in detail. Neither child's response suggests a desire to extend the role play in the way the practitioner operating in an English medium setting might have wished to pursue, exploring the role of doctors when we are ill, how to describe symptoms, or what sorts of remedies might be suggested.

Our experience of English-medium preschool provision indicates that these interventions in children's role-play are often deliberately developed to take forward current curricular themes; but in the Gaelic-medium settings, this happened rarely and in much more limited ways, because practitioners know that children do not have the Gaelic language skills to sustain these kinds of conversations. For us, this was one very significant difference in practice observed in English-medium preschool settings (in other studies) and their Gaelicmedium equivalents. It is indicative of a tension in Gaelic-medium provision between the achieving of Gaelic language goals for this educational stage, and the goals of the broader early years curriculum in Scotland. GME preschool settings in Scotland are expected to offer 3- to 5-year olds educational provision in line with the national curriculum, Curriculum for Exellence and related guidance for practitioners, as well as opportunities to learn Gaelic. As Stephen has described elsewhere (2012), the implicit theory underlying pedagogical practice in early years settings in Scotland is based on socio-cultural or Vygotskyian understanding of learning (Robson, 2012): learning is thought of as a social and collaborative endeavour between the child, her peers and the adults who care for and educate her. From this perspective language is both a key tool of society which children should acquire and a primary means through which the interactions which support learning are mediated. However, when the language of instruction is one which the children are just beginning to learn, the difficulty of achieving such goals is obvious. Anderson (2011) and Rice (2011) point out that language revitalisation programmes demand effective language pedagogy and 
practitioner development that acknowledges the scale of the challenges faced. However, Hinton (2011:308) cautions, both learners and teachers engaged in revitalising languages like Gaelic are involved in a 'pioneering process', with different goals and resources from foreign language learning, and one that needs a local response within each revitalisation programme.

Secondly, the extract illustrates the fleeting opportunities for practitioners to use Gaelic with the children, in contrast with the long periods of time during which children do not interact with practitioners at all, conversing with each other in English, or not speaking at all. Overall, in this study, we found that the amount of exposure to Gaelic experienced by children varied considerably between one setting and another, but at best, the amount of time during which they heard Gaelic spoken by other people accounted for just over half of the time; while the amount of time they spoke Gaelic themselves also varied, but was much lower, ranging from $7 \%$ in one setting to $20 \%$ in another. Much of this speech involved the production of set phrases, such as chanting the names of the days of the week, or singing ([author(s) deleted]).

In a busy nursery, practitioners have limited time to spend in casual conversation with individual children. In this case, Ms C was crossing the nursery, en route from one activity to another. She overheard the children's conversation, and, as is common with experienced practitioners, she immediately exploited the opportunity to initiate a conversation in Gaelic and to link it to the curricular theme. But, as we have seen, the children chose not to develop their role-play, and instead moved away from the home corner, to play somewhere else, away from the practitioner. This action, which may or may not have been a deliberate act of avoidance, illustrates one of the biggest challenges for practitioners in Gaelic-medium preschool settings: however gently, however expertly they attempt to introduce spontaneous Gaelic conversation into the playroom, the importance of ensuring that children are free to choose whether, when and how to learn means that children are always free not to take up these opportunities, an option often signalled by physical distancing.

In our analysis of the Gaelic-medium preschools as language learning environments, we therefore concluded that the fact that so much of the task of developing children's initial competence in Gaelic is dependent on the practitioner constitutes a major obstacle. While many practitioners are fluent Gaelic speakers, committed to the promotion of Gaelic and experienced workers in preschool settings, their impact is limited: 1) by the numbers of children for whom they are responsible, and the different kinds of activities that this might entail at any given time; and 2) by the tensions alluded to earlier between the demands of the early years curriculum and Gaelic language goals; and 3) by their lack of professional training as language educators which meant that many practitioners, while expert in other aspects of their work, had limited resources to draw on when planning to enhance children's Gaelic learning.

\section{Our Story: an app with the potential to reduce children's dependence on the practitioner for Gaelic language input}

For these reasons, our next study, Ar Stòiridh, was designed as an intervention to investigate ways of diversifying opportunities for learning Gaelic in the playroom, both to reduce demand on practitioners as the sole source of the language, and to introduce new strategies for language learning, consonant with the ethos of children's choice. 
To do this, we made use of a tablet application (app) designed by researchers at the Open University to help parents support very young children's early literacy. ${ }^{3}$ Designed for parents of children aged two or above, the app, Our Story, enables parents (and, eventually, children themselves) to upload photographs taken with the tablet's camera, to sequence them to tell a story (for example, the events of a day out in which the child has participated), to add captions and also sound files. So, in the sample text provided with the text, a picture of the child playing on a slide has a written caption ('Jamie played on the slide') and this can be accompanied by a sound file in which the same words are used, or different ones: e.g. a question such as 'What did Jamie do?', sound effects, or a commentary by the child. The story sequences can be retained, so that the parent and child can review them on other occasions, and retell the stories. The child can touch the sound button to hear the story read aloud, listen to and answer questions, or record a new commentary. It is also possible to resequence the pictures to tell new stories. The design of the app is extremely simple, to make this easy for parents and children to use together and for children to learn to use independently. The range of stories that can be constructed is virtually limitless, particularly as photographed drawings can be used as well as photos from daily life. The principal constraint is that stories can have no more than 15 pictures in sequence, though in theory it would be possible to construct a longer story with a series of sequences. One other limitation, which proved troublesome for parents in the early trials of the app and for the practitioners in our own study, was that sequences could not be saved. Once the allotted number of slots had been used, photographs and entire sequences needed to be deleted in order for new pictures and stories to be created. At the time of our study, the OU team were working to refine the original prototype.

When we first encountered the Our Story app, we were immediately struck by its potential for Gaelic-medium preschool settings. It could provide opportunities for children to hear and practise Gaelic without the practitioner always being present. As we have seen from our earlier study, opportunities for the practitioner to spend time with children as individuals or small groups are limited, and this is of concern in GME playrooms as the practitioner may be the only Gaelic speaker in the room and children's opportunities to learn the language are dependent on exposure to the language through her or his words. A resource which could provide opportunities to hear spoken Gaelic, in contexts which were familiar and made sense to the children, such as collaboratively constructed stories based on their own playroom experiences, could help to increase exposure, and thus enhance language learning as well as early literacy. Our Story was of particular value because of the possibility of linking sound files to pictures and texts. Children could listen repeatedly to the practitioner's retelling of familiar events, could be stimulated to produce responses in Gaelic as a result of carefully framed questions posed by the practitioner and could, eventually, be supported in retelling the stories themselves, in Gaelic, or in constructing new stories of their own.

Moreover, there was no need for the resource to be translated from English into Gaelic. This is a common feature of most GME preschool resources: because the Gaelic market is small, there are no companies producing children's books or other playroom resources to support early literacy in Gaelic directly. In almost all cases, these are translated from English, by the publishers themselves, by Stòlann, the national resource centre for GME, and often by the practitioners themselves, who, for example, type out the Gaelic texts of children's books and

\footnotetext{
${ }^{3}$ For more information about this app, see http://www.open.edu/openlearn/education/educational-technologyand-practice/educational-practice/reading-and-child-development-the-our-story-app-introduction. We are extremely grateful to Professor David Messer, Natalia Kucirkova and their colleagues at the Open University for allowing us to use the app for our own research purposes and for their support during the Ar Stoiridh project.
} 
stick these on top of the English texts. Such practices raise a number of issues. Firstly, even when impeccably translated, stories originally written for English readers may resonate differently when in Gaelic, particularly if the original stories depended on alliteration, rhythm, rhyme or plays on words. These are often distinctive features of books for young children, but difficult or impossible to translate from one language to another. ${ }^{4}$ Secondly, given the extent of translated resources, it is quite possible that children encounter in the GME playroom books and other resources which they have already met outside the classroom in English. There are, of course, advantages in this: a pre-existing familiarity may mean that they follow the story more easily in Gaelic, and it may enable them to make specific connections between words and phrases they already know in English and are now encountering in Gaelic. At the same time, the lack of original Gaelic resources may make children wonder about the purpose of learning the language, given that it might seem that it simply duplicates the English language world in another language. This was an issue about which preschool practitioners had raised concerns with us in the past. Thirdly, in the same vein, preschool practitioners were concerned that Gaelic could seem like a 'second class' language compared with English, because, for example, the Gaelic books had paste-over texts which inevitably looked less polished than the English books. Limited resources led to other kinds of compromises which practitioners feared could have adverse effects on children's attitudes to Gaelic: for example, in order to preserve a Gaelic language environment, children in one playroom watched DVDs with the sound turned down and a voice-over provided by the practitioner to explain the story, while in the English language playroom next door, they could watch the same DVDs with the sound on, with different actors voicing the characters, and other lively sound effects. In contrast, if Our Story was presented as a Gaelic resource from the outset, it could become something special for the children in GME playrooms, something to which the neighbouring children in English-medium playrooms were unlikely to have access.

For these reasons, we proposed an intervention study, in collaboration with Stòrlann, working with two GME state-funded nurseries, where staff had indicated that they would be interested in trialling the Our Story app, now Gaelicised as Ar Stoiridh.

\section{Design-based research}

The intervention took the form of design-based research (DBR), following the principles originally set out by Brown (1992) and subsequently refined by the Design-Based Research Collective (2003), Cobb et al., (2003), Reeves (2006) and Ormel et al. (2012). This is an approach which focuses on understanding what happens when learning environments are changed, for example by the introduction of new technologies. In the context of a review of the impact of a decade of DBR, Anderson \& Shattuck (2012: 16) provide the following definition:

"DBR is a methodology designed by and for educators that seeks to increase the impact, transfer, and translation of education research into improved practice. In addition, it stresses the need for theory building and development of design principles that guide, inform and improve both practice and research in educational contexts."

\footnotetext{
${ }^{4}$ For example, in Gaelic, rhyme involves matching vowel sounds, while consonants before and after the vowel are governed by rules of similarity but need not be identical. The classical position is set out in Knott (1934). Lyon (2010) discusses the implications of such differences between Gaelic and English for the development of literacy in GME classrooms.
} 
According to its proponents, what distinguishes DBR from other empirical approaches to educational research is its focus on twin goals: "a commitment to theory construction and explanation when solving real-world problems" (Reeves et al., 2005: 103). As Cobb et al. (2003: 10) point out, theoretical developments untested in practice will fail to engage teachers (or preschool practitioners in our case); but local developments which are successful on their own terms are unlikely to come to the attention of theorists (Barab \& Squire, 2004: 5). Desired outcomes thus entail both the furthering of the researchers' knowledge of the phenomenon in question and positive effects on learning. Collaboration between researchers and practitioners is critical to success:

"The selection and creation of the intervention is a collaborative task of both researcher(s) and practitioner(s). The creation begins with an accurate assessment of the local context, is informed by relevant literature, theory and practice from other contexts; and is designed specifically to overcome some problem or create an improvement in local practice." (Anderson \& Shattuck, op. cit.: 16)

In particular, DBR emphasises the significance of context in the development of theories about learning and argues that in order to increase capacity for educational innovation, we need to advance our knowledge of learning environments and thus our ability to design them for desired outcomes. DBR recognises that there can be many unexpected developments in the course of an intervention and that these need to be documented and the design of the intervention changed, if required, in the light of these developments: "the enacted design is often quite different from what the designers intended" (Collins et al., 2004: 19). There is also, however, a strong commitment to replicability. For this reason, an iterative model, in which intentions, actions and outcomes are carefully documented, is an important feature, to help others determine whether similar interventions could be successful in other contexts. Outcomes are understood as the interaction of resources, learners and teachers (or practitioners) to produce meaningful change. It is thus an important methodology for undertaking how, when and why educational innovations work (or fail to work) in practice.

\section{The Ar Stòiridh intervention}

The Ar Stoiridh intervention followed DBR principles in that it started from a set of 'real world' (or real playroom) problems, identified by both researchers and practitioners in our earlier work. These were: 1) generally, that the reliance on Gaelic-speaking practitioners as the sole or principal source of spoken Gaelic in GME playrooms severely limited preschool children's exposure to the language; and 2) specifically, that existing playroom resources to support Gaelic language learning were often scarce, mainly translations of English materials and typically required practitioners to make them accessible to children. The proposed intervention, using the Our Story app, was initiated by the researchers, but the decision to trial the use of the app was taken after initial discussions with staff at Stòrlann and three preschool practitioners working in two Gaelic-medium playrooms in one local authority (municipality). The research team included the authors of this paper, both experienced educational researchers with expertise in pre-school pedagogy (Stephen) and language learning and teaching (McPake). Stephen was not a Gaelic-speaker, while McPake was a learner of the language, with intermediate competence. Stòrlann appointed a fluent ${ }^{5}$ Gaelic

\footnotetext{
${ }^{5}$ There is no equivalent in Gaelic for the Anglophone concept of 'native speaker', reflecting the reality that even in homes where Gaelic is regularly spoken, children grow up with both Gaelic and English from a very early age. 'Luchd fileanta' (fluent speakers) have a certain ambivalence about defining their linguistic status in ways which might imply that one of the two languages is the more dominant. (See O'Rourke, 2011, O'Rourke \& Ramallo, 2011, and McLeod et al., 2014, for a more detailed discussion of this issue.)
} 
speaker with extensive experience of GME as consultant to the team (MacLeod): her role was to observe and discuss developments with the practitioners over the experimental phase. Of the three practitioners, two had over ten years experience in pre-school provision, and one had been working in the sector for two years. All three were local to the settings where they worked, and were fluent Gaelic speakers.

As this was a pilot study, the trial consisted of these initial discussions to develop the design of the intervention, followed by two iterations, each lasting two weeks. This work took place in spring 2012. Researchers, Stòrlann staff and practitioners met before and after the first and second iterations, and a report describing the outcomes was drafted by the researchers, reviewed by the practitioners and Stòrlann staff, and then finalised. Published in Gaelic and in English, this was designed for pre-school practitioners in GME playrooms. In October 2012 workshops based on the project were run at An t-Alltan, an annual professional development event for GME staff, with the intention of enabling others to consider whether similar interventions might be effective in their own playrooms. The data on which the following account is based include notes of the discussions at various stages, accounts of playroom practice provided by the practitioners, fieldnotes and photographs taken by the researchers and Stòrlann staff during playroom visits, and photographs, storyboards and recordings created by practitioners and children.

\subsection{Pre-intervention discussions to initiate collaboration between researchers and practitioners}

DBR makes clear the importance of engaging practitioners from the outset with the proposed change to the playroom learning environment (i.e. the introduction of the app). Our early discussions represented the first step in a collaborative endeavour to identify new learning goals for the children and ways in which these could be facilitated by the app. This work became more challenging than the researchers had initially envisaged when it emerged that neither of the nurseries had made use of tablet computers at all in the past, so that not only would the app itself be new to the practitioners and the children but the two iPads which had been purchased for the project by Stòrlann would themselves constitute a novelty in the playroom. This research took place in 2012, when tablets were not yet widely used in educational contexts, and their suitability as a tool for young children to use was the subject of debate, particularly among early years specialists. It was widely accepted that desktop and laptop computers were difficult for young children to use because they were not designed for small hands and bodies, and the standard interfaces (mouse and keyboard) were not intuitive for young children as yet unfamiliar with the shapes of letters and their layout on the keyboard, or able to read on-screen messages. Thus, up to this time, the extent of preschool children's use of computers, particularly in preschool settings, had been limited, and broader debates about young children's involvement in computer-based learning, even when favourable to the possibilities that this could engender, identified a range of logistical barriers. (For a detailed discussion of young children learning with technology in the period immediately preceding the Ar Stoiridh research, see [author(s) deleted].)

The practitioners' views on using iPads and the Ar Stoiridh app specifically were mixed. They already had desktop computers, smartboards and other technological items such as CD and DVD players, or digital cameras in the playrooms. One playroom also had a Language Master, a specialist device designed to support language learning through the use of flashcards, which could be connected to an audio tape machine to hear the words pronounced as well as see them written down. These technologies were used intermittently. The computers and smartboards had a tendency to faults which required local authority technical 
support to be fixed and therefore were not regarded as very reliable by staff. The use of the other technologies was limited by the lack of Gaelic materials, as discussed above. These were some of the specific reasons why the preschool practitioners involved in this study were less familiar than might have been expected with learning technologies, although research into learning with digital technologies in English-medium playrooms indicates that such diffidence is not limited to GME settings (Stephen \& Plowman, 2008; Plowman \& Stephen, 2013).

At the stage of our initial discussions, the practitioners identified a number of positive features and drawbacks to the iPads in general, in anticipation of their use in their playrooms. They viewed iPads favourably in that they were more portable than desktop computers or smartboards and therefore could be used more flexibly; and in that they were more ergonomically suited to young children, with a more intuitive interface. They were impressed by the ease with which you could take photographs, make notes and record sound, and thought that children would find the iPads very attractive, particularly while still a novelty. However, they were also concerned that iPads seemed fragile and would require adult supervision or specific training to ensure that children handled them appropriately; and they reckoned that they would need to establish rules limiting their use to one or two children at a time. They noted that the volume control was designed for domestic settings rather than noisy playrooms, and that this would limit the ways in which the app could be used. The reliance on wifi or $3 \mathrm{G}$ to transfer data from one source to another was problematic as their playrooms were not connected to the internet (as is typically the case in Scottish preschool settings), and this meant, for example, that practitioners would not be able to prepare work or transfer photos from one device to another, given that iPads have no USB ports.

The tenor of these early discussions makes clear the very pragmatic focus of the practitioners, in contrast to that of the researchers, who were interested in testing out their theory concerning the potential of the app as an additional source of Gaelic language input (as set out in the discussion above), and less attuned to the everyday challenges of playroom life. These initial discussions were thus important in establishing that the first iteration needed to explore the practicalities of using the app in a playroom context.

\subsection{First iteration: practitioner experimentation}

Following these discussions, the practitioners agreed to experiment with the app in their own playrooms. The researchers encouraged them to find ways of using it that fitted with current curricular themes, and with their usual playroom practice. Although the practitioners viewed the Our Story video ${ }^{6}$ provided by the Open University researchers to guide parents interested in using it with their children, there was no attempt to predetermine how the app might be used in GME playrooms. It was simply agreed that researchers would return after two weeks to find out what the practitioners - and the children themselves - had decided to do.

During this period, the practitioners used the iPad camera to take a large number of photographs of familiar playroom objects and activities, and of the children themselves at play. They used these to create a series of storyboards in which sets of objects could be grouped together (e.g. different shapes) or in which a series of activities (e.g. the steps needed to make moon sand) could be shown in sequence. They added captions in writing and recorded audio commentaries to accompany the storyboards: these ranged from one word commentaries, such as 'ceàrnag' (square) to full sentences and questions to encourage

\footnotetext{
${ }^{6}$ See: http://www.open.ac.uk/creet/main/projects/our-story
} 
children to engage more fully with the storyboards. For example a storyboard concerning observations of tadpoles included photographs of the tadpoles in the playroom at that time, at different stages, with written and oral captions such as 'a' fas casan' (growing legs) and 'a' fas earball' (growing a tail) and questions such as 'Dè a tha air atharrachadh?' (What's changed?). They began to think about how children could be encouraged to take their own pictures and create their own stories.

From the outset, as the practitioners had predicted, the children were enthusiastic about the iPad and keen to make use of it. Although some children were clearly more familiar with the use of touchscreens than others, the practitioners noticed that they learned from each other and quickly became confident users. The children enjoyed looking at the storyboards which the practitioners had produced and responding to the recorded commentaries. This included repeating key vocabulary, guessing (or remembering) what key words and phrases would be, before pressing the button to hear the recording, and responding to the questions which staff had included in relation to some of the pictures. One practitioner commented:

The children come up with some of the best suggestions. With the storyboard with the toys, one boy suggested he would guess what I was going to say [on the recording]. So he would look at the photo, say what he thought it would be in Gaelic and then use the play button to see if he was right. It was if he was testing himself-but he came up with that himself.

Often, these activities were undertaken with staff present, so there were further opportunities to point out features in the pictures or to follow up on questions or comments that the children had made; but it was also the case that the children began to use the iPads independently of the practitioners. For example, in one playroom, one child was observed showing another child who had been absent some of the activities which had taken place while she was away, as they had been recorded as a storyboard. This was a spontaneous action, unprompted by staff, and included the use of some of the Gaelic words and phrases that had been used for the storyboard. These examples indicated that the app had the potential both to support the children's Gaelic language learning generally and, more specifically, to stimulate them to use Gaelic of their own volition, without the need for the staff always to be physically present and supporting such activity.

\subsection{Second iteration: actively involving children}

After two weeks, the researchers returned to the preschool settings to review the impact of the app to date, and to discuss the possibilities for a second iteration aimed at refining the use of the app by identifying what was working well and what problems had been encountered. There were, of course teething problems. As the practitioners had anticipated, they had needed to establish rules for the handling and sharing of the iPad as so many children had wanted to use it at the same time, and they had had to make sure that those who were less familiar with the tool or less dominant characters in the playroom also got the opportunity to try it out. Nevertheless, in both settings, the app had been used extensively and the potential for the children to become more actively involved in creating their own storyboards was becoming clear. Supporting the children for this purpose became the focus of the second iteration.

In one of the settings, where the children were involved in a curricular theme about space and had constructed their own space suits, the children started taking photos of themselves wearing their suits and helmets and then recording themselves stating their own names in 
Gaelic: e.g. 'Is mise Màiri' (My name is Màiri). Then they set the other children to guess who was pictured and to try to confirm the identities by listening to the recorded messages. Because it was difficult to identify the photographed child when wearing a space helmet, and because the recorded voices were muffled for the same reason, this task became quite challenging and generated much amusement. Some of the children in the playroom became aware of the potential Photo Booth app on the iPad to distort photographs and created a similar exercise involving disguised identities.

In the other setting, following on from the earlier work on tadpoles, the children were now working on the theme of frogs. They decided to take pictures of as many frogs as they could find in their playroom environment: these were largely existing pictures of frogs (e.g. in books or wall charts) but they also photographed toy frogs in the playroom and found a chair shaped like a frog, and a frog design on food packaging. The practitioner then helped the children to add written captions to the pictures. At this stage, in neither setting did the children have a strong sense of the construction of narrative sequences: rather they appeared to conceive of the task as collecting a series of photos on a theme. However, in the frog collection, there were two photographs which could be interpreted as constituting a miniature narrative. Using a 'pop up' toy, similar to a jack-in-the-box, the children photographed a toy that appeared to be a flowerpot, with the caption 'Cait' a bheil an losgann?' (Where is the frog?), while the following photograph showed the hidden frog popping out from under the flower, with the caption 'Siud e!' (Here he is!) This perhaps constituted some initial thinking about sequencing.

\subsection{Post-intervention discussion: divergent conceptions of young children as language learners}

Because of the limited funding for this pilot study, it had been established from the outset that the intervention would have to end after four weeks, although we were aware that this initial work was more likely to raise issues than to present a definitive solution to the problems it set out to address, namely the reliance on practitioners as the main or sole source of spoken Gaelic in the playroom, and the limitations of other resources to engage the children as learners of Gaelic.

In the post-intervention discussions, it became clear that there were differences of opinion between the researchers and the practitioners in one of the settings, concerning principles of early language learning and corresponding expectations of what young children could or should do in the GME playroom. The researchers' beliefs were based on career-long engagement with theoretical work on learning in the early years, language learning, bilingualism and language revitalisation, which led them to value spontaneous communication in Gaelic as a goal for the children, to be achieved by scaffolding practices which supported opportunities for children to express their own needs and interests. The practitioners' beliefs were based on their own experiences as people who had grown up bilingual in Gaelic and English. In addition, the practitioners had career-long experience of working in preschool settings, latterly predominantly in GME, and daily engagement with the task of promoting the use of Gaelic in their own playrooms.

These practitioners' beliefs around language learning privileged a set of what might be described as performance practices, rather than spontaneous communicative practices. For example, they encouraged children to learn sets of words (such as colours or shapes) and to recite these, often in chorus. The word sets were chosen on the basis that these were the kinds of words practitioners knew the children would need in primary GME classrooms. For them, 
the children were learning Gaelic well if they could produce these words on demand and recite them in sequence when this was appropriate (e.g. days of the week, numbers etc.). This was one reason why the Language Master, described above, was seen as a useful technological aid, and superior to the Our Story app. One practitioner commented:

\section{I would like to use [the app] as a Language Master: they would have the vocabulary there and they would have the picture and they would hear the word. But [the app] is more limited because with the Language Master, you have the words for ever.}

The view that the Language Master allowed you to 'have the words for ever' partly reflects the frustration that the Our Story app had limited storage for storyboards, as described above. But this preference revealed other, underlying beliefs: for example, that there is a finite (if quite large) set of words which can be stored for use with the Language Master and need never change. In other words, the spontaneous talk that children might produce on any topic which could never be encompassed in its entirety by the Language Master, but could be captured by the app even if it subsequently had to be retired - was not the relevant factor in determining what kind of language was useful and could be learnt. The Language Master had many pre-determined sets of words - for example, on one of our visits, a series of cards with transport vocabulary was in use - but these were single words, almost always nouns, learnt without any reference to context or to the grammatical structures which would allow children to use them in conversation.

Other kinds of performances included the telling and retelling of stories: for example we observed these practitioners telling the story of the Three Billy Goats Gruff, using toy props to reinforce the meaning of the story. Children were invited to represent elements of the story using the props as the practitioners recounted the events, but they were not asked to retell the story themselves. In this context, the children's performance consisted largely of demonstrating comprehension. The practitioners believed that they did not yet have the ability to start to construct elements of the story in Gaelic. Similarly, the practitioners regularly used set phrases for playroom organisation to encourage the children to wash their hands, line up at the door, and so on. Children learned to understand these instructions by example, to begin with, but later to relate the range of tasks that might be implied by a phrase such as 'sgioblaich suas' (tidy up) to the instruction. Thus by the time they are ready to start primary school, children who had spent time in the GME nursery should be able to follow classroom instructions, understand elements of stories in Gaelic, and to have a basic productive vocabulary, consisting largely of sets of useful nouns. Both the practitioners and some GME primary teachers with whom we have discussed expectations of children's Gaelic on entry to primary school regard this as an appropriate set of competences. As researchers, we note that there is little in literature on early immersion or language revitalisation through education which might either support or challenge this view. However, we also note that the literature on children's first language development in the early years envisages a playroom environment which is linguistically rich, supporting both cognitive development and early literacy. This difference between policy expectations of a linguistically rich first language environment, on the one hand, and, on the other practitioner experience that a regulated second language environment focused on the future usefulness of the language acquired, may be a source of the tensions mentioned earlier, where the broad goals of the early years curriculum and the more instrumental goals of a language revitalisation programme can come into conflict. 
In the other setting, the practitioner focused on the practical and symbolic value of the app. She was enthusiastic about the difference it made to have a resource which could be used in Gaelic directly, given the amount of time otherwise spent on translating and adapting English-language resources. She also valued the message she felt that this conveyed to the children, that technology does not function solely in English and that the Gaelic language is a contemporary language that can be used for a range of purposes:

\section{When we have resources in Gaelic it tells the children that people care about this language and that Gaelic is not a language spoken only by the nursery staff.}

Because the pilot project was very short, we did not have time to explore these differences between the practitioners in the two different settings nor to find ways of reconciling the views of the researchers and the practitioners. However, the experience led us to understand that although DBR stresses the shared identification of the problem and potential solutions at the outset of the process, it is important to recognise that even small interventions have the potential to destabilise a playroom or a classroom, and therefore that practitioners and teachers will need support - probably through professional development in some form - to cope with the turbulence. In fact, Anderson \& Shattuck (op.cit.) recognise that major DBR projects should disrupt educational practice in a radical way (citing the work of Christensen et al., 2008) but do not discuss the practical implications of this. For these reasons, among others, our current work has shifted to focus in more detail on the professional development needs and interests of GME staff than on technological interventions. (See [Author(s) deleted]).

\section{Conclusions}

Design-based research sets the twin goals of theory building in the context of solving practical problems in the playroom or classroom. In this study, we trialed a technological intervention - the use of the Our Story app - to investigate its potential to enhance opportunities for children in GME playrooms to learn and use Gaelic. Our hypothesis was that the resource would provide an additional source of Gaelic input, apart from the practitioner, and would encourage children to listen to more spoken Gaelic and to begin to use Gaelic words and phrases themselves in responding to content already available through the app, or in creating their own content.

Although this was a short pilot study, the findings indicate that the app could indeed become an effective tool along the lines hypothesised. However, any intervention in a learning environment is likely to disrupt practice, and from practitioners' responses to disruption caused by the app, we have identified a number of underlying features of the playrooms involved in this study which may have wider relevance both for the development of theory about preschool practitioners' approach to supporting children as they learn a new language in immersion-style settings, perhaps particularly in MLM playrooms; and for practical responses, in terms of developing more effective provision.

On the basis of this work, we argue that there has been insufficient attention in the literature on MLM early years education to the tension between the expectation deriving from current thinking about effective preschool education that playrooms are environments where children develop their social and cognitive competence through language, and the expectation deriving from language revitalisation programmes that children in MLM playrooms should make a strong start on the learning of what, for most, is a second language, not previously encountered. This places a heavy burden on practitioners to meet all of these expectations 
without specialist professional development which enables them to explore and resolve these tensions in ways which work in their own playrooms. Further iterations of the intervention might have enabled us to begin to identify ways of doing this, specifically in relation to the playrooms involved in the project. In the absence of that opportunity, the focus of our current work is on the nature of the professional development that could support practitioners facing these challenges.

9118 words

\section{References (author(s) publications deleted for reviewing process)}

Anderson, G. (2011). Language Hotspots: what (applied) linguistics and education should do about language endangerment in the twenty-first century. Language and Education, 25(4): 273-289.

Anderson, T. \& Shattuck, J. (2012). Design-based research: a decade of progress in designbased research? Educational Researcher, 41 (1): 16-25.

Bailey, B. (2007). Heteroglossia and boundaries. In M. Heller (ed.) Bilingualism: A Social Approach. Basingstoke: Palgrave Macmillan.

Barab, S. \& Squire, B. (2004). Design-based research: putting a stake in the ground. The Journal of the Learning Sciences, 13 (1): 1-14. Available at:

http://website.education.wisc.edu/kdsquire/manuscripts/jls-barab-squire-design.pdf (accessed 10 July 2014).

Bòrd na Gàidhlig (2012). National Gaelic Language Plan 2012-2017. Inverness: Bòrd na Gàidhlig. Available at:

http://www.gaidhlig.org.uk/Downloads/National\%20Gaelic\%20Langauge $\% 20 \mathrm{Plan} \% 2020$ 12\%20-\%202017.pdf (accessed 13 July 2014).

Bòrd na Gàidhlig (2013). National Gaelic Education Strategy: Gaelic-Medium Early Years Strategy 1, 2013-2016. Available at:

http://www.gaidhlig.org.uk/Downloads/National\%20Gaelic\%20Education\%20Strategy $\% 2$ 0(Early\%20Years).pdf (accessed 13 July 2014).

Brown, A. (1992). Design experiments: theoretical and methodological challenges in creating complex interventions in classroom settings. The Journal of the Learning Sciences, 2 (2): 141-178.

Campbell, J. (1950). Gaelic in Scottish Education and Life: Past, Present and Future. Edinburgh: W. \& A.K. Johnson for the Saltire Society.

Creese, A. \& Blackledge, A. (2010). Translanguaging in the bilingual classroom: a pedagogy for learning and teaching? Modern Language Journal, 94 (1): 103-115.

Creese, A. \& Blackledge, A. (2011). Separate and flexible bilingualism in complementary schools: multiple language practices in interrelationship. Journal of Pragmatics, 43 (5): 1196-1208.

Christensen, C., Horn, M. \& Johnson, C. (2008). Disrupting class: how disruptive innovation will change the way the world learns. New York: McGraw-Hill.

Cobb, P., Confrey, J., diSessa, A., Lehrer, R. \& Schauble, L. (2003). Design experiments in educational research. Educational Researcher, 32 (1): 5-8.

Collins, A., Joseph, D. \& Bielaczyc, K. (2004). Design research: theoretical and methodological issues. Journal of the Instructional Sciences, 13 (1): 15-42.

Devine, T. (1994). Clanship to Crofters' War. Manchester: Manchester University Press.

Dorian, N.C. (1981). Language Death: The Life Cycle of a Scottish Gaelic Dialect. Philadelphia: Pennsylvania University Press. 
Fishman, J. (1972). Domains and the relationship between micro- and macro-sociolinguistics. In J. Gumperz \& D. Hymes (eds.). Directions in Sociolinguistics. The ethnography of speaking. New York: Holt, Reinhart and Winston (407-434).

Galloway, J. (nd) Gaelic Education Data 2011-12. Inverness: Bòrd na Gàidhlig. Available at: http://www.gaidhlig.org.uk/Downloads/Gaelic\%20Education\%20Data\%202011-12.pdf (accessed 13 July 2014).

García, O. (2007). Foreword. In S. Makoni \& A. Pennycook (eds.) Disinventing and Reconstituting Languages. Clevedon: Multilingual Matters.

García, O. (2009). Bilingual Education in the $21^{\text {st }}$ Century: A Global Perspective. Chichester: Wiley-Blackwell.

Heller, M. (2007). Bilingualism as ideology and practice. In M. Heller (ed.) Bilingualism: A Social Approach. Basingstoke: Palgrave Macmillan.

Hermanto, N., Moreno, S. \& Bialystok, E. (2012). Linguistic and metalinguistic outcomes of intense immersion education: How bilingual? International Journal of Bilingual Education and Bilingualism, 15 (2): 131-145.

Hickey, T. (1997). Early Immersion Education in Ireland. Dublin: Institiúid Teangeolaíochta Éireann/Linguistics Institute of Ireland.

Hickey, T. (2013) Early bilingual education In: C. Chapelle, C.A (ed.) The Encyclopedia of Applied Linguistics. Oxford: Blackwell Wiley.

Hickey, T., Lewis, G., \& Baker, C. (2014). How deep is your immersion? Policy and practice in Welsh-medium preschools with children from different language backgrounds. International Journal of Bilingual Education and Bilingualism, 17 (2): 215-234.

Hinton, L. (2001). Language revitalization: An overview. In K. L. Hale \& L. Hinton (eds.) The Green Book of Language Revitalization in Practice. San Diego, CA: Academic Press.

Hinton, L. (2011). Language revitalization and language pedagogy: new teaching and learning strategies. Language and Education, 25 (4): 307-318.

Hornberger, N. (2008). Can Schools save Indigenous Languages? Policy and Practice on Four Continents. London: Palgrave Macmillan.

Knott, E., (1934). Irish Syllabic Poetry 1200-1600. Cork: Cork University Press (2 ${ }^{\text {nd }}$ Ed.)

Lyon, F., (2010). Early Intervention in Gaelic-medium Education: Creating and evaluating a tool for assessing phonological awareness. Unpublished $\mathrm{PhD}$ these, University of Strathclyde.

MacKinnon, K. (1978). Education and Social Control: the case of Gaelic Scotland. Scottish Educational Studies, 4: 125-137.

MacKinnon, K. (2006). Gaelic to English language shift 1972-2001. In W. McLeod (ed.) Revitalising Gaelic in Scotland. Edinburgh: Dunedin Press.

May, 2004. Māori-medium Education in Aotearoa/ New Zealand. In J. Tollefson \& A. Tsui (eds.) Medium of Instruction Policies: Which Agenda? Whose Agenda? Mahwah, NJ: Lawrence Erlbaum Associates.

McCarty, T. (2002). A Place to be Navajo: Rough Rock and the Struggle for Selfdetermination in Indigenous Schooling. Mahwah, NJ: Lawrence Erlbaum Associates.

McCarty, T. (2008). Schools as strategic tools for indigenous language revitalization: lessons from Native America. In N. Hornberger (ed.) Can Schools Save Indigenous Languages? Basingstoke: Palgrave Macmillan.

McKenney, S. \& Reeves, T., (2013). Systematic review of design-based research progress: is a little knowledge a dangerous thing? Educational Researcher, 42 (2): 97-100.

McLeod, W., O'Rourke, B. \& Dunsmore, S. (2014). 'New Speakers' of Gaelic in Edinburgh and Glasgow. A Report for Soillse. Available at: http://www.soillse.ac.uk/downloads/New\%20Speakers\%20Final\%20Report 2 3.pdf (accessed 13 July 2014). 
Mitchell, R. (1992). The 'independent' evaluation of bilingual primary education: a narrative account. In C. Alderson \& A. Beretta (eds.) Evaluating Second Language Education. Cambridge: Cambridge University Press.

Murray, J. \& Morrison, C. (1984). Bilingual Primary Education in the Western Isles, Scotland. Stornoway: Acair.

Ormel, B., Pareja Roblin, N., McKenney, S., Voogt, J. \& Pieters, J., (2012): Researchpractice interactions as reported in recent design studies: still promising, still hazy. Educational Technology Research \& Development. DOI:10.1007/s11423-012-9261-6. Available at: http://link.springer.com/article/10.1007/s11423-012-9261-6/fulltext.html (accessed 10 July 2014).

O’Rourke, B. (2011). Whose Language Is It? Struggles for Language Ownership in an Irish Language Classroom. Journal of Language, Identity \& Education, 10 (5): 327-345.

O'Rourke, B. \& Ramallo, F. (2011). The native-non-native dichotomy in minority language contexts: comparisons between Irish and Galician. Language Problems \& Language Planning, 35: 139-59.

Paterson, L. (2003). Scottish Education in the Twentieth Century. Edinburgh: Edinburgh University Press.

Plowman, L, \& Stephen C. (2013). Guided interaction: exploring how adults can support children's learning with technology in preschool settings. Hong Kong Journal of Early Childhood. 12 (1): 15-22.

Pollock, I. (2010). Learning from Learners: Teachers in Immersion Classrooms. In G. Munro and I. Mac an Tàilleir (eds.). Coimhearsnachdan Gàidhlig An-diugh/Gaelic Communities Today. Edinburgh: Dunedin Academic Press (117-25).

Reeves, T., (2006). Design research from the technology perspective. In J. Akker, K. Gravemeijer, S. McKenney \& N. Nieveen (eds.). Educational Design Research. London: Routledge (86-109).

Reeves, T., Herrington, J. \& Oliver, R., (2005). Design research: A socially responsible approach to instructional technology research in higher education. Journal of Computing in Higher Education, 16 (2): 97-116.

Rice, S. (2011) Applied field linguistics: delivering linguistic training to speakers of endangered languages. Language and Education, 25 (4): 319-338.

Robson, S. (2012) Developing thinking and understanding in young children. Abingdon: Routledge.

Stephen, C. (2012). Looking for theory in preschool education. Studies in Philosophy and Education, 31(3): 227-238.

Stephen, C. \& Plowman L., (2008). Enhancing learning with ICT in preschool. Child Development and Care, 178 (6): 637-654.

Tedick, D., Christian, D. \& Fortune, T. (2011). The future of immersion education: An invitation to 'dwell in possibility'. In D. Tedick, D. Christian \& T. Fortune (eds.) Immersion Education: Practices, Policies, Possibilities. Bristol: Multilingual Matters. 